\title{
A CONTABILIDADE TRADICIONAL E A CONTABILIDADE BASEADA EM VALOR"
}

\author{
Adriana Maria Procópio de Araújo \\ Professora Doutora do Depto. de Contabilidade e Atuária da FEA/USP - Ribeirão Preto \\ E-mail: amprocop@usp.br \\ Alexandre Assaf Neto \\ Professor Doutor do Depto. de Contabilidade e Atuária da FEA/USP - Ribeirão Preto \\ E-mail: assaf@terra.com.br
}

\section{RESUMO}

Importantes avanços estão sendo constatados na forma de atuação das empresas. A moderna gestão de empresas descarta a postura convencional da busca pela medição do lucro e rentabilidade e cede espaço a uma gestão voltada à riqueza dos acionistas. O crescimento da competitividade costuma, ainda, exigir vultosos investimentos para ganhos adicionais de market share, avaliados, muitas vezes, como de difícil recuperação econômica.

Criar valor aos acionistas demanda estratégias financeiras e novas medidas de sucesso empresarial, voltadas a agregar riqueza aos seus proprietários. Diante disso, exige-se da contabilidade uma atuação mais destacada e sofisticada, visando a cobrir as necessidades de informações dos vários agentes de mercado, dentro de um ambiente de moderna gestão das empresas.

Os objetivos do estudo são: (i) constatar a importância da contabilidade na moderna administração empresarial; (ii) sensibilizar o pesquisador e profissional contábil da premente necessidade de modernização do sistema contábil; (iii) apresentar os fundamentos de um modelo de gestão baseada no valor, comparativamente aos procedimentos tradicionais de administração focada nos lucros; e (iv) constatar a relevância da informação contábil sob a ótica da essência econômica.

Palavras-chave: contabilidade, finanças, ajustes contábeis, valor de empresas.

\section{ABSTRACT}

Important advances are observed in the way companies perform. Modern company management discards the conventional profit and yield measurement position and gives room to management directed towards shareholder wealth. The growth of competitiveness usually demands great investments with a view to additional market share earnings, whose economic recovery is usually evaluated as difficult.

Creating value for the shareholders demands financial strategies and new corporate success measures, aimed at adding wealth for its proprietors. Bearing this in mind, a more outstanding and sophisticated performance is demanded from accounting with a view to covering the information needs of the various market agents in a modern company management environment.

This study aims to: (i) disclose the importance of accounting in modern company management; (ii) make researchers and accounting professionals aware of the urgent need to modernize the accounting system; (iii) present the foundations of a value-based management model, in comparison with the traditional profit-focused management procedures; and (iv) disclose the relevance of accounting information from the perspective of economic essence.

Keywords: accounting, finance, accounting adjustments, corporate finance.

\footnotetext{
*Artigo baseado em Tese de Doutorado defendida no EAC/FEA-USP - Campus capital, de título: Ajustes da Contabilidade Tradicional para uma Contabilidade Baseada em Valor. Recebido em $03.06 .03 \cdot$ Aceito em $23.10 .03 \cdot 2^{\text {a }}$ versão em 29.10 .03
} 


\section{INTRODUÇÃO}

Um problema econômico extremamente relevante, e comum a qualquer pessoa, empresa, nação etc. é o da alocação de recursos. Num mercado extremamente competitivo, as organizações buscam, aceleradamente, medidas flexíveis com relação ao melhor gerenciamento dos recursos disponíveis. Medidas essas nas diversas áreas da atividade, assegurando a continuidade de participação no mercado.

Num passado recente, a viabilização econômica de investimentos estruturava-se basicamente no aumento de preços de produtos e serviços oferecidos à comunidade nacional e internacional. Essa prática, de certa maneira, despreocupava seus investidores. Não obstante, esse cenário alterou-se substancialmente.

A exigência por produtos e serviços com qualidade, a custos menores, torna-se prática rotineira em economias abertas. A postura do consumidor nessas economias migra de uma atitude passiva para uma ativa. Constata-se forte demanda por produtos e serviços que de maneira geral agreguem mais vantagens aos consumidores.

Não é somente a postura do consumidor que incentiva a eficácia na gestão das organizações. Atualmente, dado o crescimento vultoso da competitividade, as organizações necessitam de investimentos, muitas vezes, expressivos. O objetivo desses investimentos resume-se na obtenção de possíveis ganhos adicionais ao custo do capital investido. A gestão de uma organização tende a sair da posição convencional de medição do lucro e rentabilidade para a gestão voltada à criação de riqueza.

Vários são os recursos utilizados por uma organização. Alguns aparecem de forma similar, como, por exemplo, humanos, tecnológicos, financeiros etc. Outros envolvem especialidades e são inerentes a determinada atividade, como, por exemplo, equipamentos de alta precisão para a extração de petróleo. Não obstante, alguns são identificados em qualquer tipo de entidade e independe da atuação no mercado, como é o caso do capital. Administrá-los com eficiência já não basta. Os gestores das organizações buscam medidas mais consistentes de desempenho e controle desses recursos.

Nesse contexto de administração de recursos, questiona-se quais são os objetivos de uma empresa.
Para Solomon (1977) o objetivo geral da empresa, que tem sido mais comumente apresentado para fim de análise teórica, é a maximização dos lucros.

Sob outro prisma, para Porterfield (1976) o objetivo da empresa, ao tomar suas decisões financeiras, deve ser o de maximizar o bem-estar econômico de seus proprietários. Pode-se resumir que as decisões financeiras de qualquer pessoa estejam estruturadas em três fundamentos básicos: i) onde investir fundos e em que quantias; (ii) quanto pagar de dividendos e (iii) onde levantar fundos e em que montante. Para uma empresa, pelos menos dois fundamentos são identificados: (i) determinar o nível e a forma de utilização de seus fundos e, (ii) planejar suas fontes de fundos. Vale ressaltar que as decisões financeiras da empresa são inevitáveis, apresentando-se de forma contínua.

Uma empresa pode pressupor vários objetivos. Ainda que seu fim estabelecido seja rigorosamente de maximização da riqueza de seus proprietários (ou de seu valor de mercado), a empresa pode ser justificada e analisada a partir de vários outros objetivos. O propósito de maximização do valor de mercado de uma empresa é conseqüência (resultado) dos vários objetivos que podem ser estabelecidos para a empresa.

$\mathrm{Na}$ tentativa de um consenso de interpretações entre os principais autores, optou-se, com base em Solomon (1977), pelo objetivo da empresa como sendo o da maximização da riqueza dos acionistas. "A razão lógica fundamental do objetivo da maximização da riqueza, é que essa maximização reflete a utilização mais eficiente dos recursos econômicos de uma sociedade, promovendo, assim, a maximização da riqueza econômica da sociedade". (Solomon, 1977, p.40).

Nesse aspecto, deixa implícito que para se chegar à referida maximização, é condição necessária a maximização da riqueza dos acionistas. Esse propósito, embora sintético, retrata de maneira geral o porquê da existência de uma empresa.

Constata-se ainda que toda teoria de finanças empresariais, em todo mercado, adota e aceita como o objetivo da empresa, a maximização da riqueza dos acionistas. Nesse momento, a empresa necessita de informações que permitam aos seus acionistas verificar se os seus fins estão sendo alcançados. Inserese, nesse contexto, o papel da contabilidade. 
A finalidade primordial da contabilidade é atuar como instrumento de administração. Especificamente, é dar suporte ao planejamento da entidade quando da identificação e determinação dos objetivos, bem como na análise de alternativas e projeção futura.

Acompanha, ainda, o processo de execução de tomadas, de decisões, envolvendo a utilização de recursos econômicos e, finalmente, controlando e analisando o resultado das decisões tomadas. Não obstante, esses não são os únicos instrumentos para auxiliar a administração de entidades, mas são de suma relevância.

Um sistema tradicional de contabilidade tem como finalidade oferecer à empresa relatórios que elucidem a medição voltada para o lucro e a rentabilidade. Essa postura de administração está cedendo espaço para a gestão mais arrojada dos recursos que envolvem o capital, ou seja, a organização tem buscado uma gestão voltada à criação de riqueza.

Essa visualização da moderna gestão das empresas passa a exigir uma atuação mais destacada e sofisticada da contabilidade, cobrindo as necessidades de informações dos vários agentes do mercado.

O conceito de gestão baseada em valor estrutura-se em premissas da value-based management (VBM), ou seja, administração baseada em valor. Entretanto, a contabilidade tradicional, independente dos critérios de avaliação dos ativos e passivos, não contempla, de maneira global, informações que permitam verificar se o objetivo de maximização da riqueza está sendo alcançado.

Como conseqüência desse cenário, alguns usuários das informações contábeis, como por exemplo, os gestores, demandam modelos que elucidem a criação ou não de riqueza por parte das entidades. Assim, percebe-se uma lacuna no que tange às informações fornecidas por tal sistema. Cabe ressaltar que a contabilidade tem potencial para fornecer tais informações, basta desenvolver novos modelos para atender semelhante demanda, ou seja, criar mecanismos para sua aplicabilidade.

Atualmente, é notório saber que a contabilidade, como reflexo de sua estrutura convencional, deixa a desejar quando usuários solicitam informações sobre resultados obtidos voltados para a criação de valor. Em verdade, essa observação justifica a crescente participação de profissionais não contábeis atuando fortemente em elaboração de dados que resultem em informações consistentes para os diversos usuários da contabilidade. Se a contabilidade é peça fundamental da arte de administrar, por que não atuar profundamente em questões que auxiliem a administração de uma entidade? Obviamente, várias seriam as respostas a esse questionamento.

Na tentativa de buscar uma contribuição específica para a área contábil, visando ao fornecimento de informações úteis e fidedignas aos usuários, a questão de pesquisa desse trabalho tem a seguinte formatação: (i) a contabilidade deve informar resultado revelador à análise da maximização da riqueza do acionista? Completando essa questão: (ii) a contabilidade, de acordo com os princípios fundamentais de contabilidade, é capaz de oferecer medidas de lucro, rentabilidade e valor ao seu usuário principal?

A busca por respostas a esse questionamento envolverá um estudo profundo em todas as questões que, direta ou indiretamente, interfiram nos resultados a serem obtidos. Para tanto, a seguir, será tratado um conjunto de objetivos que envolvem o tema já referido.

O objetivo do trabalho é, num primeiro momento, constatar a relevância da informação contábil sob a ótica da essência econômica e, num segundo momento, desenvolver as premissas de um sistema contábil apresentando medidas de lucro e rentabilidade, ajustando-o ao objetivo de valor da entidade.

Em resposta à primeira questão, efetuou-se um estudo com relação à finalidade de uma empresa e a aplicação de um sistema contábil que atenda tal finalidade. Esse estudo prioriza o aprofundamento da teoria contábil e da teoria das finanças. A ênfase está estruturada na utilização da informação contábil pelos usuários principais de uma entidade.

No segundo questionamento, necessário se faz a estruturação de um sistema contábil voltado para uma gestão que traduza para os acionistas informações sobre a variação de sua riqueza. Sistema esse que parte da contabilidade baseada em seus princípios fundamentais de contabilidade, identifica e 
estrutura os ajustes necessários para se chegar numa contabilidade direcionada às premissas de uma gestão fundamentada no conceito de valor. Para tanto, desenvolveu-se um exemplo completo aplicando os referidos ajustes e constatando o papel da contabilidade nesse contexto.

A teoria contábil, também, pode estar embasada no aspecto de teoria descritiva ou prescritiva. As teorias descritivas selecionam quais informações são apresentadas aos usuários da contabilidade. As prescritivas recomendam quais dados devem ser comunicados e como devem ser apresentados.

$\mathrm{Na}$ contabilidade, as pesquisas podem aparecer tanto da forma descritiva quanto prescritiva. $\mathrm{Na}$ linha do raciocínio, interagindo com os métodos de dedução e indução, as pesquisas não são tão desenvolvidas como outrora. No campo da linguagem, principalmente de forma pragmática, a verificação de uma teoria é feita pela sua utilização. Essa abordagem é a mais usual entre os modernos teóricos e também serviu de base como metodologia utilizada para este estudo.

Para o desenvolvimento do trabalho, num primeiro momento, foi feito um estudo da teoria contábil, especificamente da sua estruturação de acordo com os princípios fundamentais de contabilidade. A ênfase desse estudo concentrou-se na essência econômica da informação contábil. Foram identificados os ajustes necessários para se desenvolver um sistema contábil aplicado a atender às expectativas dos investidores no sentido de medição da criação do valor da empresa.

No contexto contábil brasileiro, a originalidade deste trabalho encontra-se justamente do desenvolvimento de uma contabilidade voltada para a gestão baseada em valor, ou seja, simular uma situação contábil e aplicá-la de acordo com a legislação e pronunciamento, tanto contábil quanto fiscal, e essa mesma situação aplicá-la à gestão baseada em valor, com análise dos resultados. Completando essa contribuição, foi demonstrado um exemplo contábil para a gestão baseada em valor, aplicado em sua íntegra, levando-se em consideração os ajustes propostos.

Algumas limitações são identificadas neste estudo. Uma delas é a utilização da contabilidade moldada nos princípios fundamentais de contabilidade aplicados no Brasil, não se estendendo às normas internacionais de contabilidade. Eventualmente, em cada ajuste, poderão ser abordadas questões de práticas efetuadas de acordo com a regulamentação internacional de contabilidade. A justificativa para tal limitação deve-se ao fato de que, para a realidade brasileira, ainda não se tem pesquisa profunda para aplicações práticas de contabilidade voltada para a gestão baseada em valor. Ressalte-se, ainda, que o estudo prioriza a gestão das empresas e não a estrutura conceitual contábil.

Uma outra limitação está direcionada à identificação dos ajustes envolvidos em questões de interpretação duvidosa. Na prática, podem aparecer ajustes não mencionados neste estudo, por conseqüência de atividade econômica, produtos inerentes à questão sazonal, legislação específica etc.

\section{REVISÃO DA LITERATURA}

Vários são os enfoques do estudo da contabilidade. Enfatizar a importância hierárquica de cada um dos enfoques não é o objetivo principal deste trabalho. Dois motivos estruturam essa decisão. O primeiro motivo se fundamenta na condição da falta de medidas justas para comprovar qual enfoque é mais importante, tornando o sistema subjetivo. O segundo é que cada segmento de usuário da informação contábil pode querer determinar sua real importância.

Isso posto, neste estudo, buscou-se a identificação de uma abordagem que oferecesse sustentação a uma contabilidade aplicada a uma gestão direcionada à medição da criação de valor de uma entidade. Em verdade, buscou-se fundamentação teórica para responder à questão do objetivo da pesquisa, ou seja, se a contabilidade deve informar resultado revelador à análise da maximização da riqueza do acionista, optando-se pelo enfoque econômico da teoria contábil.

De acordo com Hendriksen \& Van Breda (1999), diversos enfoques têm sido adotados num esforço de resolver problemas em contabilidade. São eles: fiscal, legal, ético, econômico, estrutural e comportamental. Na tentativa de sintetizar as abordagens anteriormente descritas, a tabela 1 demonstra quais os principais questionamentos que podem ser levantados acerca dos enfoques. 


\section{Tabela 1 - Perguntas a Fazer - Abordagens da Teoria Contábil}

\begin{tabular}{l|l}
\hline \multicolumn{1}{c|}{ Abordagens } & \multicolumn{1}{c}{ Questionamentos } \\
\hline Fiscal & Qual é a situação fiscal? \\
Legal & O que é exigido por lei? Há alguma regulamentação específica para este setor? \\
Ético & O que é correto? Esta é uma apresentação justa? \\
Econômico & Que efeito exercerá este procedimento contábil sobre a economia? Que efeito exercerá este \\
& procedimento contábil sobre os acionistas? O procedimento permite a divulgação completa dos fatos? \\
& Que efeito exercerá sobre outros grupos de interesse? \\
Comportamental & Por que a administração deseja fazer esta escolha? \\
Estrutural & Há alguma regra específica relativamente a esta situação? Qual é a definição de receita?
\end{tabular}

Fonte: baseado em HENDRIKSEN, Eldon. \& VAN BREDA, Michael F. Teoria da Contabilidade. SP: Atlas, 1999.

\section{2 - A Teoria Contábil sob o Enfoque Econômico}

Escolher uma abordagem da teoria contábil por si só não basta. Diante das possibilidades mencionadas no tópico 1.1, fica evidente que a contabilidade é elaborada para atender a diversos usuários. No presente estudo, optou-se pela abordagem econômica e tal escolha se resume na argumentação de que a contabilidade deverá ser utilizada como instrumento de medição da criação de valor da entidade. Essa abordagem preocupa-se com os questionamentos, objeto deste estudo, ou seja, efeitos dos procedimentos contábeis para os acionistas e para os grupos de interesses (stakeholders), não se restringindo, portanto, à medição de rentabilidade e lucro.

Algumas argumentações fundamentam semelhante decisão. Uma incursão na literatura contábil permite identificar que autores contábeis expressivos objetivam a contabilidade sob a óptica econômica. ludícibus (1993) cita que o objetivo da contabilidade pode ser resumido no fornecimento de informações econômicas para os vários usuários, de forma que propiciem decisões racionais.

Hendriksen \& Van Breda (1999) enumeram e discutem várias posições acerca do objetivo da contabilidade. Mencionam primeiramente um enfoque voltado para o cálculo e apresentação do lucro líquido, resultante de regras específicas de realização e vinculação num balanço, relacionando período corrente a períodos futuros.

Posteriormente, abordam um objetivo como sendo o de fornecer informação financeira confiável sobre os recursos econômicos e as obrigações de uma empresa. Citam ainda uma outra argumentação que define contabilidade como sendo algo mediador num conflito social de distribuição de renda e riqueza. Resumindo, os referidos autores não se posicionam e não deixam transparecer nenhum objetivo claro da contabilidade.

Em um pronunciamento do Accounting Principles Board (APB) AICPA (1970), o Financial Accounting Standards Board (FASB) sintetiza os objetivos da contabilidade ressaltando que a divulgação financeira deve fornecer informações úteis para investidores e credores atuais e em potencial, bem como para outros usuários que visem à tomada de decisões na empresa.

Assumindo a postura de que a contabilidade objetiva a divulgação de informações financeiras e econômicas aos diversos níveis de usuários, constatase mais uma vez a utilidade e confiabilidade de tais informações. Vários são os interesses dos usuários das informações contábeis e várias são as abordagens da teoria contábil, como enfatizadas anteriormente. Muitos são os usuários das informações contábeis que utilizam tais abordagens, não necessariamente excludentes.

De maneira geral, a contabilidade está direcionada à apuração de um resultado no final de um determinado período, o qual indicará se a entidade obteve sucesso ou não. Em outras palavras, serão mensurados o lucro do negócio e sua eventual rentabilidade. Essa informação é constante em qualquer abordagem escolhida.

Em se tratando da abordagem econômica, já enfatizada como relevante para o processo decisório na entidade, essa informação deixa a desejar. A contabilidade tradicional está direcionada à apuração do lucro em sua forma original, ou seja, pela variação patrimonial em períodos distintos. 
Essa forma tradicional perde em essência econômica quando o interesse dos usuários da informação contábil extrapola o conceito de lucro e necessita de informações voltadas para a geração de riqueza. (...) "a contabilidade, enquanto ciência, tem uma rica base conceitual da qual devemos nos valer e, interagindo de forma multidisciplinar com os demais ramos do conhecimento, buscar a construção de uma via alternativa à Contabilidade tradicional, cuja base conceitual é inadequada para modelar as informações destinadas ao uso dos gestores". (Almeida; Parisi; Pereira, 1999, p.369). Ainda segundo os autores, a contabilidade tradicional está voltada à mensuração de eventos econômicos passados e com certo grau de ineficiência.

Embora o conceito de lucro contábil seja um assunto minucioso, após sintetização dos diversos conceitos dos órgãos normativos contábeis acerca do mesmo, admitindo-se que a gestão financeira almeja pelo conceito de valor, o lucro contábil não é totalmente apropriado para o auxílio no processo de gestão da empresa.

\section{FINANÇAS EMPRESARIAIS E A CONTABILIDADE}

Estudaram-se os princípios de finanças empresariais, fazendo uma ligação entre a teoria contábil e a administração financeira, principalmente no aspecto de valorização dos recursos que envolvem o patrimônio de uma entidade. Nesse ponto, constatase a importância da execução da contabilidade voltada para atender às expectativas dos usuários (acionistas) e não somente para a medição do lucro e rentabilidade.

A definição do lucro econômico é um assunto que vem sendo discutido e aprimorado por pesquisadores durante décadas. Para se chegar ao lucro econômico, mister se faz a conceituação do capital. "A poupança nos leva à natureza do capital. Capital, no sentido de capital-valor, é simplesmente a renda futura descontada ou, em outras palavras, capitalizada. O valor de uma propriedade, ou de direitos à riqueza, é seu valor como fonte de renda e é calculado descontando essa renda esperada". (Fisher, 1988, p.24).

O precursor da definição de lucro como sendo o montante que pode ser consumido sem a redução do capital é Adam Smith. Hicks (1946) reforça e avança esse conceito de que lucro é o montante que uma pessoa pode gastar durante um período e, ainda, estar tão bem no final do período quanto no início.

Completando esse raciocínio, Hendriksen \& Van Breda (1999) colocam que lucro é um fluxo de serviços por unidade de tempo; o capital é a representação concreta de serviços futuros, e o lucro é o desfrute desses serviços num dado período. Acrescentam definindo o lucro como sendo o excedente após a preservação do bem-estar.

Ainda segundo os mesmos autores, para que a preservação da riqueza (capital) seja avaliada, necessária se faz que a referida avaliação seja em sua totalidade (ativos e passivos). Completando: "a variação dos ativos e passivos durante o período é combinada ao fluxo de caixa gerado pela empresa para chegar ao lucro da entidade nesse período". (Hendriksen \& Van Breda, 1999, p.192).

Não obstante, será alcançada a medida do lucro de acordo com a maneira pela qual os ativos e passivos estiverem sendo avaliados. As medidas tradicionais podem ser enumeradas da seguinte forma: (i) lucro tradicional, em que os ativos e passivos são avaliados pelo custo histórico; (ii) lucro econômico, considerando o valor de mercado da entidade, e (iii) outros conceitos, em que se utilizam medidas baseadas em expectativas dos fluxos de caixa futuros e também nos preços de mercado dos ativos.

No contexto empresarial, o lucro pode ser entendido como o resultado obtido com o uso do capital. Avançando esse raciocínio, a empresa não visa somente a interesses próprios, busca, também, um fluxo de riqueza aos seus acionistas.

De acordo com Copeland, Koller e Murrin (2000), o lucro econômico é o resultado entre o valor do capital investido, multiplicado pelo retorno sobre o capital investido, menos o custo de oportunidade do capital. Esse parece ser o conceito mais apropriado para 0 assunto desenvolvido no escopo deste trabalho, ou seja, sob o ponto de vista da teoria das finanças.

\section{1 - Custo de Oportunidade, Custo de Capital e Juros sobre o Capital Próprio}

Alguns instrumentos complementares estão relacionados com a mensuração do valor de uma entidade. $O$ custo de oportunidade, o custo de capital e os juros sobre o capital próprio são utilizados para essa 
finalidade. Conceituá-los com ênfase na abordagem econômica é o propósito do presente tópico.

$O$ custo de oportunidade vem sendo conceituado por vários autores. Na tentativa de resumir alguns dos conceitos mais utilizados, pode o custo de oportunidade ser definido como a melhor alternativa de investimento desprezada quando na escolha de um outro, de mesmo risco.

A entidade observada na condição de sistema aberto relaciona-se com diversas áreas. Necessita de recursos das mais variadas formas, como, por exemplo, humanos, tecnológicos, materiais, informacionais, financeiros entre outros. Nesse contexto, a entidade pode obtê-los por meio de diversos agentes econômicos. Esses agentes econômicos resumem-se em fornecedores de recursos, podendo aparecer sob a forma de acionistas, debenturistas, instituições financeiras, entidades fornecedoras de materiais etc. O capital é a somatória de tais fontes de financiamento exigíveis ou não da entidade e, portanto, geram custo pela captação.

O custo de capital pode ser conceituado como a remuneração mínima esperada pelos proprietários de capital em relação à entidade investida. O ideal é proporcionar retorno superior a tal remuneração objetivando a geração de valor para a entidade.

Em verdade, o custo do capital é um instrumento que serve como parâmetro para a entidade tomar decisões sobre investimentos. Essas decisões recebem o respaldo de uma taxa referencial, que serve como limite mínimo para o retorno dos investimentos, eliminando alternativas incapazes de gerar valor para a entidade.

Toda vez que a entidade não for capaz de remunerar seus credores e acionistas na taxa mínima de retorno esperada (custo de oportunidade), constatam evidências de destruição de valor. "(...) o custo do capital próprio $\left(k_{c}\right)$ de uma empresa é definido pelo retorno $(k)$ requerido por seus acionistas ao investirem seus recursos no empreendimento". (Martins \& Assaf Neto, 1991, p.482).

Os autores citados completam o conceito argumentando que a empresa ao captar recursos no mercado acionário ou reter parte dos lucros auferidos, deverá aplicá-los em ativos rentáveis, objetivando produzir um retorno que possa remunerar seus acionistas em nível equivalente às suas expectativas. Assim sendo, a remuneração mínima exigida pelos acionistas representa, em última análise, o custo do capital próprio da empresa.

Obviamente, a empresa almeja aplicar recursos em ativos que remunerem os acionistas em suas expectativas. Caso isso não ocorra, o reflexo será imediatamente observado na desvalorização do preço de mercado da ação refletindo na riqueza dos acionistas.

O custo de capital permite a identificação de uma taxa mínima de atratividade dos investimentos de uma empresa e sua capacidade de agregar valor. $O$ custo do capital equivale aos retornos exigidos pelos credores da empresa (instituições financeiras, debenturistas etc) e por seus proprietários. Identifica o retorno que a empresa deve auferir em seus investimentos de maneira a remunerar suas fontes de financiamento.

O CMPC é obtido pelo custo de cada fonte de capital ponderado por sua respectiva participação na estrutura de financiamento. Sua fórmula básica é a seguinte: $\mathbf{C M P C}=\mathbf{W}_{1} \times \mathbf{K}_{\mathbf{i}}+\mathbf{W}_{\mathbf{2}} \times \mathbf{K}_{\mathrm{e}}$. A tabela 2 demonstra essa fórmula.

\section{Tabela 2 - Fórmula do Custo Médio Ponderado do Capital}

\begin{tabular}{l|l}
\hline Nomenclatura & Significado \\
CMPC & Custo médio ponderado de capital das várias fontes de financiamento utilizadas pela empresa. \\
$\mathrm{W}_{1}, \mathrm{~W}_{2}$ & Respectivamente, proporção de fundos de terceiros e próprios na estrutura de capital. \\
$\mathrm{K}_{1}$ & Custo do capital de terceiros. \\
$\mathrm{K}_{\mathrm{e}}$ & Custo do capital próprio.
\end{tabular}

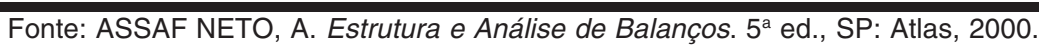

A utilização do custo médio ponderado de capital fundamenta-se na questão de que a empresa, normalmente, mantém uma certa relação entre passivos exigíveis e patrimônio líquido dentro de determinadas faixas.
A comparação entre projetos com fontes específicas de financiamento pode comprometer a escolha das melhores inversões de recursos, sendo, portanto, recomendável o custo médio ponderado 
de capital, com o objetivo de eliminar as possíveis distorções.

Com relação ao CMPC, algumas situações deverão ser levadas em consideração. Basicamente são quatro as situações a serem esclarecidas: (i) limitações nas proporções de fundos de terceiros e próprios; (ii) estrutura ótima de passivo em relação ao patrimônio líquido; (iii) estratégia financeira, e (iv) risco.

A questão da remuneração do capital próprio, também denominada de juros sobre o capital próprio, não é assunto recente em contabilidade. Muito se discute sobre o conceito de lucro contábil no sentido de considerar todo o ganho auferido pelo capital investido pelos sócios.

O âmago da questão é a separação entre a mera remuneração do capital, se aplicado em outras circunstâncias, e a remuneração desse capital auferida pela empresa em sua totalidade. A inclusão dos juros sobre o capital próprio nas demonstrações de resultados, conforme sugerido pela legislação vigente, não deve ter a pretensão de apurar o custo de oportunidade do acionista. O conceito de custo de oportunidade do capital é mais rigoroso, representando o retorno da melhor alternativa de investimento, desprezada pelo acionista, ao selecionar outra oportunidade de mesmo risco. Equivale à taxa mínima de atratividade requerida pelos investidores. $\mathrm{O}$ uso do custo de oportunidade do capital próprio na apuração dos resultados permite que se avalie a efetiva remuneração do acionista.

Cabe ressaltar, como limitação da utilização dos juros sobre o capital próprio, que o mesmo não leva em consideração o risco inserido no negócio, a taxa de oportunidade do capital próprio e a correção do Patrimônio Líquido. A legislação brasileira limita o percentual de juro sobre o capital próprio em relação ao patrimônio líquido da empresa.

\section{2 - Medidas de Desempenho Tradicionais}

Com relação às medidas de desempenho, necessário se faz a distinção entre os indicadores conhecidos como tradicionais e os indicadores estruturados no conceito de valor. Lopo et al. (In: FIPECAFI, 2001) questionam a origem dos indicadores baseados no valor e ressaltam que algumas medidas de desempenho tradicionais são: (i) resultado do exercício; (ii) retorno sobre o investimento (Return on Investment - ROI); (iii) retorno sobre o patrimônio líquido (Return on Equity - ROE); (iv) retorno operacional sobre o investimento; e (v) lucro residual (Residual Income-RI).

Não obstante, questiona-se a classificação da medida de desempenho tradicional, denominada lucro residual. Em verdade, tal medida está extremamente relacionada ao valor. Segundo Copeland; Koller; Murrin (2000), medidas contábeis tradicionais, como o lucro líquido, ignoram o custo de oportunidade do capital necessário para gerar o lucro. O retorno sobre o capital investido ignora o crescimento como fonte de criação de valor.

Lopo et al. (In: FIPECAFI, 2001) classificam o lucro residual como sendo uma medida de desempenho tradicional. Não obstante, pela concepção apresentada, isso é questionável. Ainda segundo o mesmo autor, o lucro residual demonstra que a criação de riqueza ocorre sempre que a entidade investir em projetos cujos retornos superem o custo de capital.

Conceituando, "o lucro residual pode ser entendido como os recursos gerados pela entidade que sobram após a dedução dos juros reais aplicados sobre o capital investido pelos sócios". (Lopo et al. In: FIPECAFI, 2001, p.244). Além da limitação derivada da utilização de critérios contábeis tradicionais, deixa a desejar quanto à identificação de taxas de juros utilizadas.

Sob outro enfoque, "o lucro residual é definido como o lucro líquido operacional após impostos Net Operating Profits After Taxes (NOPAT) menos uma despesa pelo capital investido". (RAPPAPORT, 2001, p.144).

Por envolver conceitos embasados na concepção do valor, o lucro residual aproxima-se consideravelmente das medidas de desempenho fundamentadas em tais premissas. A sua classificação original, ou seja, considerada como tradicional pode ser revertida para a categoria de medida de desempenho baseada em valor.

\section{3 - Medidas de Desempenho Baseadas no Valor}

Na concepção de técnicas modernas de gestão financeira, as medidas tradicionais de desempenho cedem espaço para ferramentas mais arrojadas. Em verdade, verifica-se o refinamento de técnicas já existentes e a busca pela eficácia do sistema de gestão. 
A gestão baseada em valor prioriza a maximização do valor da empresa e, para tanto, se utilizam técnicas e processos gerenciais orientados para tal premissa. Nessa abordagem, a ênfase está nos direcionadores de valor (value drivers), sendo o custo de capital o mais utilizado.

De maneira geral, as entidades investem numa diversidade de ativos. $\mathrm{O}$ objetivo de tal investimento resume-se na maximização do seu valor. Em termos reais as entidades almejam por ativos que agregam maior valor para a empresa. Não obstante, necessário se faz a utilização de medidas gerenciais que traduzam para gestores tais informações.

Objetivando atender à demanda verificada anteriormente, surgem alguns indicadores de mensuração de valor. Dentre os indicadores mais tradicionais e conhecidos, destacam-se o Economic Value Added $(\mathrm{EVA}){ }^{\circledR}$ e o Market Value Added (MVA), ${ }^{\circledR 1}$ que serão abordados nos próximos tópicos. Existem outros indicadores que se baseiam nos mesmos fundamentos do EVA ${ }^{\circledR}$. Segundo Lopo et al. (In: FIPECAFI, 2001), alguns exemplos podem ser: (i) Cash Flow Return on Investment (CFROI); (ii) Shareholder Value Added (SVA); (iii) Adjusted Economic Value Added (AEVA) e (iv) Refined Economic Value Added (REVA).

Ainda, segundo os mesmos autores, o CFROI é um produto oferecido pela Boston Consulting Groupe sua formatação é similar à taxa interna de retorno (TIR). Convertem-se dados de probabilidade em fluxos de caixa brutos. Dois são os processos realizados: (i) mensura-se e ajusta-se o fluxo de caixa pela inflação e o compara com o investimento corrigido realizado pelos proprietários do capital e (ii) utiliza-se o índice apurado no item anterior com uma taxa interna de retorno.

O SVA estrutura-se no desconto de fluxos de caixa futuros a valor presente, calculando assim o valor da empresa. Seus precursores são: Alfred Rappaport e LEK/Alcar Consulting Group. A análise de desempenho baseia-se na comparação do desempenho real do fluxo de caixa com o projetado. "A abordagem do valor para o acionista estima o valor econômico de um investimento ao descontar os fluxos de caixa previstos pelo custo de capital. Esses fluxos de caixa, por sua vez, servem como ponto de partida para os retornos dos acionistas com base em dividendos e valorização do preço da ação. (...) Enquanto o valor para o acionista caracteriza o valor econômico absoluto resultante do cenário previsto, o SVA aborda a mudança no valor ao longo do período de previsão (...) a criação de valor para o acionista resulta do investimento da empresa a taxas acima do custo de capital exigido pelo mercado de capitais". Rappaport (2001, p.50 e 70).

Quanto ao Adjusted Economic Value Added (AEVA) e Refined Economic Value Added (REVA), segundo Lopo et al. (In: FIPECAFI, 2001), parecem ser versões adaptadas do EVA ${ }^{\circledR}$.

A ênfase do AEVA é utilizar o valor corrente de ativos substituindo o valor contábil. No REVA utilizase o valor de mercado da firma do período anterior substituindo o valor contábil. Os dois indicadores adotam o fluxo de caixa, ressaltando que os métodos norteadores de tais procedimentos são por demais complexos.

\subsection{1 - Valor Econômico Agregado}

Na concepção do valor econômico, como o objetivo enunciado de qualquer empresa é gerar, em suas decisões financeiras, um retorno que remunere as expectativas de rendimentos de seus proprietários de capital, a comparação do retorno sobre o investimento (ROI) com o CMPC permite identificar se a empresa está agregando ou destruindo valor econômico.

Tal comparação pode estar consubstanciada em um sistema de gestão. Nesse sistema de gestão, o valor econômico agregado ou economic value added, é conceituado como uma medida de desempenho econômico. É conhecido pela sigla EVA ${ }^{\circledR}$. Foi desenvolvido por economistas, e surgiu há mais de duzentos anos, com o objetivo inicial de medida de desempenho e sistema de gestão.

Passou para a denominação efetiva de EVA ${ }^{\circledR}$ após vários estudos efetuados pela Stern Stewart a partir dos anos oitenta. Em sua fórmula original, $E V A^{\circledR}$ nada mais é do que o valor econômico agregado ou adicionado de uma entidade, ou seja, o resultado da empresa que exceder à remuneração mínima exigida pelos proprietários de capital. Na ênfase atual, EVA ${ }^{\circledast}$ é a estrutura para um sistema completo de gerência

${ }^{1}$ EVA e MVA são marcas registradas da Stern Stewart \& Co. 
financeira e remuneração variável que pode auxiliar o processo de tomada de decisões das empresas.

O lucro residual "é o lucro menos o retorno desejado do investimento em dinheiro". (HORNGREN; FOSTER; DATAR, 2000, p.663). O EVA ${ }^{\circledR}$ em sua fórmula original é a simples noção de lucro residual, ou seja, é o lucro operacional deduzidos os impostos e encargo sobre o capital; é o lucro que excede o custo do capital utilizado para realizar o lucro operacional.

Para Grant (1997), o economic value added é definido como a diferença entre o lucro líquido operacional da empresa (antes do imposto) e o custo total do capital expresso em termos monetários. Completa, ainda, que o EVA ${ }^{\circledR}$ serve como um modelo de mensuração de sucesso das finanças corporativas, porque está estritamente alinhado com a maximização da riqueza solicitada pelos acionistas. Não obstante, nada impede de ser calculado após o imposto de renda, como é muito usual e conveniente.

Em seu nível mais básico, o EVA, uma sigla para valor econômico agregado, é uma medida de desempenho empresarial que difere da maioria das demais ao incluir uma cobrança sobre o lucro pelo custo de todo o capital que uma empresa utiliza. Mas o EVA é muito mais do que uma simples medida de desempenho. É a estrutura para um sistema completo de gerência financeira e remuneração variável que pode orientar cada decisão tomada por uma empresa, da sala do conselho até o chão da fábrica; que pode transformar uma cultura corporativa; que pode melhorar as vidas profissionais de todos na organização, fazendo com que sejam mais bem-sucedidos; e que pode ajudá-los a produzir maior valor para os acionistas, clientes e para eles próprios. (...) a maneira mais óbvia pela qual o EVA auxilia gerentes a tomarem melhores decisões é cobrando suas operações pelo custo de todo o capital. (EHRBAR, 1999, p.01).

O autor sintetiza a questão explicando que o encargo sobre o capital induz gerentes a utilizarem ativos com maior cuidado, ou seja, dando ênfase aos custos associados. Em verdade, permite a avaliação periódica do custo do capital em cada decisão a ser tomada, inclusive com a análise dos reflexos entre custos operacionais e custos de capital.
Para Rappaport (2001), o EVA ${ }^{\circledR}$ é uma versão do lucro residual. Segundo o autor, o EVA ajusta o valor contábil ao chamado "valor contábil de livro" adicionando equivalentes de capital próprio com o objetivo de uma aproximação do caixa total investido na empresa.

Do ponto de vista contábil, o $\mathrm{EVA}^{\circledR}$ nada mais é do que a aplicação efetiva do custo do capital próprio. "Chama-se de Valor Econômico Adicionado ao lucro que a empresa produz depois de deduzir do lucro contábil o Custo do Capital Próprio. Ou seja, representa o ganho que sobra depois de considerar o Custo do Capital Próprio como se fosse despesa". (MARTINS, 1996, p.432). Na referida concepção, o valor econômico adicionado inicia-se pelo lucro contábil baseado nos princípios fundamentais de contabilidade, sendo em seguida, ajustado.

Dois princípios básicos de finanças empresariais podem ser cobertos quando se trabalha com valores de $E V A^{\circledR}$ projetado. São eles: (i) maximização da riqueza dos acionistas; (ii) apuração do valor da empresa que depende do retorno futuro esperado pelos investidores, excluído o custo do capital.

O lucro contábil não garante, por si só, a remuneração do capital. Métodos alternativos deverão cuidar dessa análise. $\mathrm{O} \mathrm{EVA}^{\circledR}{ }^{\circledR}$ é utilizado pelas entidades que optaram pela gestão baseada em valor e não simplesmente como um índice de análise financeira.

Um sistema de gestão financeira é um conjunto de políticas, procedimentos, medidas e métodos financeiros que ajudam e controlam as operações e estratégias de uma empresa. Isso é o $E V A^{\circledR}$. Matematicamente, pode-se explicar esse instrumento do sistema de gestão da seguinte maneira: $E A^{\circledR}=$ LOP - (CMPC- INVT), onde:

$\begin{array}{ll}\mathrm{LOP}= & \text { lucro operacional líquido após tributação } \\ \mathrm{CMPC}= & \begin{array}{l}\text { custo percentual de capital } \\ \text { INVT }=\end{array} \\ \text { investimento total }\end{array}$

Obviamente existem vantagens e limitações. Embora o EVA ${ }^{\oplus}$ não se constitua em uma novidade, consegue resgatar conceitos simples e fundamentais de uma gerência voltada para análise de valor. Dada a sua simplicidade de compreensão e capacidade de conscientizar gestores sobre perspectivas futuras do negócio, o $E V A^{\circledR}$ tem sido muito atrativo para auxílio no processo de tomada de decisões. 
Pelo menos uma importante limitação pode ser identificada nesse processo.

O EVA ${ }^{\circledR}$, quando calculado de maneira geral, leva em consideração os dados contábeis tradicionais, ou seja, tais informações tendem a ocultar fatos que se tratados isoladamente, interfeririam com relevância no resultado apurado. Na tentativa de uma síntese dos conceitos anteriormente abordados, pode-se dizer que o $E V A^{\circledR}$ mostra o lucro residual, ou seja, o excesso. Quando trazido a valor presente, o $E A^{\circledR}$ representa a riqueza gerada na empresa, dentro de um período determinado.

\subsection{2 - Market Value Added (MVA) ${ }^{\circledR}$ e Goodwill}

Tanto o EVA ${ }^{\circledR}$ quanto o Market Value Added (MVA ${ }^{\circledR}$ advêm da abordagem da administração baseada em valor, ou Value Based Management (VBM). São indicadores de mensuração de valor que surgiram para atender à forte demanda por posturas gerenciais mais arrojadas no mundo empresarial.

Nessa abordagem de gerenciamento, as aspirações, técnicas de análises e processos gerenciais são totalmente voltados para a maximização da riqueza da empresa, conseqüentemente, do acionista.

Com relação ao $\mathrm{EVA}^{\circledR}$, reafirma-se que é uma medida de lucro residual que orienta a gerência sobre a geração de valor da empresa. É considerado residual, pois leva em consideração a remuneração do capital. O EVA ${ }^{\circledR}$, quando apurado das demonstrações financeiras da empresa, reflete o valor residual referente ao período, podendo inclusive ser projetado.

Não obstante, deixa a desejar quando na mensuração da efetiva riqueza criada ou consumida pela empresa num determinado período. Tentando minimizar tal problema, trabalha-se com valores projetados. Isso posto, para se chegar a essa criação efetiva de riqueza, necessário se faz o cômputo do comportamento das cotações das ações no mercado acionário.

Segundo Ehrbar (1999) o valor de mercado agregado $(\mathrm{MVA})^{\circledR}$ é a medida definitiva de criação de riqueza. Supera outras medidas por ser a diferença entre entrada de caixa e saída de caixa, ou seja, o que investidores colocam na empresa como capital e o que poderiam receber na venda das ações no mercado corrente.
Em outras palavras, MVA $^{\circledR}$ é equivalente à estimativa do mercado de capitais do valor presente líquido ou NPV (método do fluxo de caixa descontado para avaliação de investimentos) de uma empresa. Essencialmente, é a diferença entre o valor total de mercado de uma empresa e o valor dos fundos nela investidos.

Para Grant (1997), essa associação positiva entre as duas medidas $\left(E V A^{\circledR}\right.$ e $\left.M V A^{\circledR}\right)$ de sucesso financeiro indica favoravelmente que o $E V A^{\circledR}$ demonstra informações positivas aos investidores sobre a capacidade da empresa em gerar valor econômico agregado no futuro.

(...) "o MVA ${ }^{\circledR}$ é automaticamente ajustado para o risco, já que os valores de mercado de empresas incorporam julgamentos de investidores quanto a risco além de desempenho (...) é uma medida que pode ser utilizada para comparar diretamente os desempenhos de empresas em setores diferentes ou até mesmo em países diferentes (...) o objetivo financeiro maior de toda empresa deveria ser criar tanta riqueza para acionistas - tanto MVA - quanto possível". (EHRBAR, 1999, p.36).

Alguns pontos fundamentais interferem na eficiência do cálculo do MVA ${ }^{\circledR}$. São eles: (i) as mudanças no nível geral da bolsa de valores poderão sobrepujar a contribuição das ações da gerência no curto prazo; (ii) ○ MVA ${ }^{\circledR}$ somente poderá ser calculado se a empresa tiver suas ações negociadas em bolsa e tiver um preço de mercado e (iii) mesmo para empresas de capital aberto, o MVA ${ }^{\circledR}$ somente deverá ser calculado no consolidado da empresa.

O MVA ${ }^{\circledR}$ de uma empresa pode ser considerado o valor presente do montante pelo qual investidores esperam que os lucros futuros excedam ou fiquem aquém do custo de capital.

Para efeito desse estudo, opta-se pelo EVA ${ }^{\circledR}$ por ser um indicador contextualizado nas premissas do MVA $^{\circledR}$. Concluindo, o EVA ${ }^{\circledR}$ é um direcionador de valor, indicando o comportamento do $\mathrm{MVA}^{\circledR}$, ou seja, dando base para o seu cálculo. Não obstante, para se calcular o $\mathrm{MVA}^{\circledR}$, necessário se faz a aplicação de ajustes para converter o valor contábil em valor econômico. Matematicamente tem-se: MVA = EVA / CMPC.

Com relação ao goodwill, Hendriksen \& Van Breda (1999) colocam como sendo o mais importante ativo intangível na maioria das empresas. Ressaltam que 
é um ativo de tratamento complexo, resultando em atenção especial na questão da mensuração.

Segundo os autores, três são os enfoques principais com relação à avaliação: (i) utilizando-se de avaliação de atitudes favoráveis em relação à empresa; (ii) por meio do valor presente da diferença positiva entre lucros futuros esperados e o retorno sobre o investimento total, e, (iii) por meio de uma conta de avaliação, apura-se a diferença entre o valor total da empresa e as avaliações dos ativos líquidos tangíveis e intangíveis.

Martins (1972) conceitua o goodwill associado à definição de ativo como sendo o resultado econômico que se espera obter no futuro. Numa outra colocação, resume que "o goodwill pode ser considerado como o resíduo existente entre a soma dos itens patrimoniais mensurados individualmente e o valor global da empresa". (MARTINS et al. In: FIPECAFI, 2001, p.124).

O conceito de goodwill pode ser equiparado ao conceito amplo do MVA ${ }^{\circledast}$. O MVA ${ }^{\circledR}$ e o goodwill caracterizam-se pela diferença entre o valor total de mercado de uma empresa e o valor dos fundos nela investidos. A prerrogativa que determina a diferença entre as aplicações diz respeito à forma de avaliação.

A avaliação do investimento pelo $\mathrm{MVA}^{\circledR}$, normalmente, é feita pelo custo corrigido, enquanto que no conceito amplo do goodwill essa avaliação pode ser efetuada pelo custo de reposição. Uma outra colocação pode ser feita na comparação do goodwill com relação ao EVA ${ }^{\circledR}$. Ao relacionar o EVA ${ }^{\circledR}$ com o custo médio ponderado de capital, pode-se chegar ao goodwill da empresa.

\section{4 - A Informação Contábil Baseada em Valor}

A postura tradicional de contabilidade com ênfase no lucro e rentabilidade já não atende, em sua plenitude, aos anseios dos usuários. Necessário se faz que as informações traduzam realidade empresarial aos seus gestores. Realidade essa que se preocupa demasiadamente com o conceito de valor.

Demonstrações contábeis tradicionais perdem muito em essência econômica das informações divulgadas. Com as mutações econômicas constantes, as entidades precisam traduzir em suas posições patrimoniais tais reflexos.
Não obstante, muito tem se evoluído nessa questão. Recentes estudos e pesquisas na área contábil atentam demasiadamente para o fator essência econômica da informação. O parâmetro escolhido dentre os usuários é a criação de riqueza das entidades. Para se chegar à medição da criação de riqueza, necessário se faz uma estruturação das informações contábeis baseada em valor.

Inúmeros são os conceitos atribuídos a valor. No presente estudo, o conceito de valor se restringirá a dois: (i) valor patrimonial e (ii) valor econômico. Por valor patrimonial entende-se o resultado da soma dos bens que constituem o patrimônio total de uma entidade em dado momento. Por valor econômico entende-se o fluxo futuro esperado (potencial de resultados) por uma entidade, consubstanciando-se no valor da empresa.

Nesse aspecto, o conceito pragmático de maximização da riqueza dos acionistas como objetivo geral da empresa é ampliado. Nesse conceito, agrega-se o interesse dos stakeholders. Portanto, a informação contábil baseada em valor deverá atentar-se não somente para as solicitações dos acionistas como também dos stakeholders.

De acordo com Gitman (1997), uma empresa atenta aos stakeholders evitará, conscientemente, medidas que possam ser prejudiciais a eles, ou seja, afetar sua riqueza, transferindo-a à empresa. Completa, ainda, que, em se mantendo um bom relacionamento entre as partes, vista como responsabilidade social da empresa, a mesma poderá atingir melhor seu objetivo de maximização da riqueza dos acionistas por meio da cooperação - em lugar do conflito - com seus stakeholders.

Constatado o objetivo da empresa em maximizar a riqueza do acionista, foi considerando a prerrogativa de que o investimento do acionista revela atratividade econômica somente quando a remuneração oferecida for suficiente para remunerar o custo de oportunidade do capital próprio aplicado no negócio. Se uma empresa for capaz de remunerar aos seus proprietários somente até o limite de suas expectativas mínimas de retorno, o seu valor de mercado restringe-se ao montante necessário que se despenderia para edificá-la, ou seja, ao valor de reposição de seus ativos (fixos e de giro). O valor é criado ao acionista somente quando as receitas de vendas superarem a todos os dispêndios incorridos, inclusive o custo de oportunidade do capital próprio. 
Continuando nessa linha de pensamento, quando o valor da empresa exceder ao valor de realização de seus ativos será indício de que houve agregação de riqueza. Esse é o conceito do Market Value Added $(\mathrm{MVA})^{\circledR}$, também conhecido como goodwill. Cabe ressaltar que alguns autores renomados, como os da escola americana, não fazem uma ligação direta entre o $\mathrm{MVA}^{\circledR}$ e o goodwill.

\section{INFORMAÇÕES CONTÁBEIS ESTRUTURADAS PARA A GESTÃO BASEADA EM VALOR}

Talvez a questão em iminência ao se tentar estruturar dados contábeis a uma gestão direcionada ao valor seja: isso é mesmo necessário? Ao tentar buscar argumentações a tal questionamento, mister se faz retornar à questão primária sobre o objetivo de uma empresa. Ao se determinar que o objetivo principal de uma empresa é o de maximizar a riqueza do acionista, inevitavelmente que informações relacionadas à criação de valor deverão existir.

Diante desse cenário, qual informação contábil poderá ser útil, ou mais adequada, a uma administração preocupada com a criação do valor? A contabilidade estruturada de acordo com os princípios contábeis não atende, em sua plenitude, à gestão baseada em valor.

Alguns ajustes deverão ser efetuados, como por exemplo: pesquisas e desenvolvimento, investimentos estratégicos, contabilização de aquisições, reconhecimento de despesas, depreciação, encargos de reestruturação, impostos etc.

A informação contábil estruturada para o administrador preocupado com a questão do valor da empresa, deverá, no mínimo, ser ajustada pelos itens anteriormente mencionados. Vários são os modelos que, de alguma forma, objetivam apurar o valor de uma empresa.

Dada a complexidade do assunto, busca-se, nesse estudo, apresentar os principais modelos de avaliação de empresas. Segundo Martins (In: FIPECAFI, 2001), os mais usuais resumem-se a oito, a saber: (i) modelo de avaliação patrimonial contábil; (ii) modelo de avaliação patrimonial pelo mercado; (iii) modelo do valor presente dos dividendos; (iv) modelo baseado no patrimônio líquido de ações similares; (v) modelo de capitalização dos lucros; (vi) modelo dos múltiplos de faturamento; (vii) modelo dos múltiplos de fluxo de caixa e (viii) modelo baseado no $E A^{\circledR}$.

O modelo baseado no $E V A^{\circledR}$ será objeto de estudo e análise para a interpretação dos ajustes efetuados neste estudo. A escolha está estruturada em algumas premissas. Uma delas é que entre os modelos mais estudados, esse parece atender com maior grau de eficiência à questão da relevância e confiabilidade da informação contábil. Outra premissa está relacionada com a objetividade das informações que estruturam o modelo. Uma terceira premissa é a cobertura dos princípios básicos de finanças, o da maximização da riqueza dos acionistas e o da apuração do valor da empresa, considerando o retorno futuro esperado pelos investidores, excluído o custo do capital.

\section{AJUSTES CONTÁBEIS PARA A GESTÃO BASEADA EM VALOR}

Esboçada a contabilidade aplicada à gestão baseada em valor, esse tópico trata do desenvolvimento dos ajustes contábeis necessários para a elaboração de um sistema contábil nos preceitos de apuração do valor. Nesses ajustes, foram levados em consideração cada órgão normativo contábil e a legislação vigente, além de exemplos de aplicações.

Vários são os ajustes contábeis necessários para sair de um sistema contábil objetivando lucro e rentabilidade e se chegar às premissas de valor. Tais ajustes diferem quanto ao segmento de mercado em que empresa se enquadra, fatores tecnológicos, localização geográfica, enfim, particularidades de cada entidade.

Não obstante, serão abordados os principais ajustes para se chegar à informação de criação do valor. Primeiramente, para o cálculo do EVA ${ }^{\circledR}$ de uma empresa, necessário se faz a identificação de quais ajustes serão efetuados nas contas estruturadas pelos princípios fundamentais de contabilidade.

A empresa de consultoria Stern Stewart, “(...) por exemplo, identificou mais de 160 ajustes em potencial a serem feitos nos GAAP e nos tratamentos contábeis internos, todos podendo melhorar as cifras medidas de lucros operacionais e de capital. Qualquer mudança nos ajustes contábeis renderá uma cifra de EVA diferente, é claro". (EHBAR, 1999, p.131). 
Quanto aos ajustes contábeis necessários, alguns são determinantes e clássicos. Tais ajustes incluem, entre outros quesitos: o timing do reconhecimento de despesas e receitas, investimentos passivos em títulos negociáveis, ativos securitizados e outros tipos de financiamento fora do balanço, encargos de reestruturação, inflação, conversão de moedas estrangeiras, valoração de estoques, reservas contábeis, reconhecimento de devedores duvidosos, ativos intangíveis, impostos, pensões, despesas pós-aposentadoria, despesas de marketing, questões de intangíveis e outras relativas a aquisições e investimentos estratégicos.

Ainda segundo Ehrbar (1999), alguns ajustes clássicos são: (i) pesquisa e desenvolvimento; (ii) investimentos estratégicos; (iii) contabilização de aquisições; (iv) lançamento de despesas; (v) depreciação; (vi) encargos de reestruturação; (vii) impostos e (viii) ajustes ao balanço.

Copeland; Koller; Murrin (2000) mencionam que os mercados emergentes em geral possuem princípios contábeis diferentes daqueles dos mercados desenvolvidos. Algumas diferenças contábeis devem ser levadas em consideração quando comparado o sistema contábil tradicional com um sistema estruturado em valor, entre elas: (i) critérios de correção monetária nas demonstrações financeiras; (ii) reavaliação de ativos; (iii) método de equivalência patrimonial para efeito de consolidação das demonstrações; (iv) contabilização e reconhecimento das operações de arrendamento mercantil - leasing; (v) critérios para reconhecimento de ativos financeiros - valor de mercado ou custo histórico; (vi) possibilidade de descontar passivos ou contas a receber de longo prazo para o valor presente; (vii) métodos de depreciação; (viii) divulgação de contingências e (ix) impostos, inclusive diferimento.

Comparando a posição dos autores analisados, verifica-se que alguns ajustes são comuns e outros não. Na tentativa de um consenso entre esses autores, na estrutura proposta no escopo desse estudo, a seguir serão considerados os ajustes anteriormente mencionados. Os ajustes propostos são: (i) critérios de correção monetária nas demonstrações contábeis; (ii) reavaliação de ativos; (iii) equivalência patrimonial; (iv) arrendamento mercantil; (v) apropriação de gastos com pesquisas e desenvolvimento; (vi) reconhecimento de passivos de longo prazo a valor presente; (vii) métodos de depreciação; (viii) divulgação de contingência; (ix) impostos e diferimento; (x) ativos intangíveis goodwill e (xi) custo de oportunidade do capital.

Tal estrutura levou em consideração a legislação brasileira vigente, os órgãos que normatizam e regulamentam as questões contábeis e, por último, o ajuste baseado no valor. Após a fundamentação teórica para cada ajuste proposto foi apresentado um exemplo completo aplicado a uma empresa.

\section{1 - Sistema Contábil Baseado em Valor}

Elaborar um sistema de informação contábil baseado em valor não é tarefa simples. Em verdade, tornase um sistema em até certo ponto audacioso. Tal prerrogativa fundamenta-se em algumas premissas: (i) a contabilidade tradicional não considera o custo de oportunidade do capital próprio; (ii) a contabilidade efetuada de acordo com os princípios fundamentais de contabilidade não demonstra informações relacionadas com valor; (iii) a legislação societária vigente está desatualizada em pontos fundamentais que, de certa forma, interferem no valor do patrimônio da empresa; (iv) os órgãos de classe e regulamentadores, como o CFC, IBRACON e CVM não se posicionam com relação ao disclosure da informação contábil ao usuário com relação à medida de valor.

Enfim, muitas outras questões poderiam ser levantadas no tocante às dificuldades encontradas para se efetuar um sistema contábil voltado para o valor.

Os contadores têm lutado de forma hercúlea durante o último quarto de século para fazer com que demonstrativos de resultados e balanços reflitam mais precisamente a condição financeira e o desempenho das corporações. (...) a distância crescente, por assim dizer, entre os GAAP e a realidade decorre de uma tendência extremamente conservadora da profissão contábil. Quando contadores se deparam com uma escolha entre várias maneiras de tratar um item, quase que invariavelmente escolhem a opção que colocará a menor cifra no demonstrativo de resultados ou no balanço patrimonial. Eles imediatamente baixam todos os gastos em intangíveis como pesquisa e desenvolvimento e treinamento de funcionários mesmo que as empresas façam essas despesas apenas porque esperam um retorno positivo no futuro. (EHRBAR, 1999, p.129) 
A entidade deseja muito mais que isso. Necessita de medidas que ofereçam indicações e feedback confirmando ou refutando as decisões de alocação de capital. Não obstante, esse estudo almeja preencher uma lacuna perfeitamente visível no sistema contábil tradicional. Trabalhar com dados que traduzam lucro e rentabilidade não é mais suficiente para as empresas assegurarem sua continuidade, enquanto trabalhar com dados que traduzam valor passa a ser questão de sobrevivência do negócio.

Em inúmeras vezes, a empresa obtém lucro contábil, distribui uma parcela desse montante e, sem perceber, não está conseguindo gerar riqueza. Possivelmente essa empresa se descapitalizará e apresentará forte tendência à descontinuidade. Nesse momento, o objetivo é traçar alguns ajustes necessários para a elaboração de um sistema contábil baseado no valor. Tal prerrogativa enfatiza a contabilidade partindo dos moldes tradicionais, sendo ajustada para se obter parâmetros relacionados ao valor. Não é o objetivo deste estudo mudar a estrutura conceitual contábil, nem os princípios fundamentais de contabilidade. $O$ intuito é trabalhar com um sistema contábil totalmente voltado para questões gerenciais, com o propósito de atender aos usuários principais em consonância com o descrito no escopo deste trabalho, ou seja, maximizar a riqueza dos acionistas.

\section{CONCLUSÕES}

O presente estudo envolveu pesquisa e questionamento em diversos assuntos. Não obstante, tais assuntos merecem ser refletidos e repensados com o intuito de contribuir para o crescimento e evolução do pensamento contábil.

Não obstante, para o esclarecimento das etapas anteriormente mencionadas, buscou-se o aprofundamento da teoria contábil e um estudo da teoria das finanças.

No primeiro objetivo proposto no trabalho, ou seja, se a contabilidade deve informar resultado revelador à análise da maximização da riqueza do acionista, constatou-se o seguinte: (i) a teoria contábil aborda vários enfoques aplicados à contabilidade; dentre esses enfoques, ressaltase o econômico; (ii) na abordagem econômica, o lucro está estruturado nos preceitos do valor; (iii) a gestão baseada em valor não considera como medidas válidas o lucro e a rentabilidade e sim o valor agregado; (iv) a contabilidade, sendo instrumento de informação gerencial, deverá informar ao seu usuário principal dados que retratem, além do lucro e da rentabilidade, o valor; (v) o sistema contábil aplicado aos princípios de valor atende ao usuário principal e esse, por sua vez, pode analisar a maximização de sua riqueza durante o período; (vi) a informação contábil, nessas condições, torna-se relevante e útil para a abordagem proposta.

Como apresentado durante o estudo, a contabilidade tradicional não atende em sua plenitude aos anseios dos usuários. De maneira geral os profissionais da área são preparados para apurar o resultado da entidade visando ao lucro e à rentabilidade, deixando a desejar no quesito valor, em última análise, os contadores não mensuram o custo do capital próprio.

No segundo objetivo proposto, se a contabilidade de acordo com os princípios fundamentais, oferece medidas de lucro, rentabilidade $e$ valor ao seu usuário principal, constatou-se o seguinte: (i) análise dos pontos divergentes entre a contabilidade tradicional e a contabilidade aplicada ao conceito de valor; (ii) constatação de ajustes contábeis a serem efetuados na contabilidade tradicional; (iii) elaboração de um modelo contábil, partindo de um elenco sistematizado de contas para o desenvolvimento do mesmo; (iv) aplicação prática de um exemplo, utilizando os ajustes propostos e analisando os resultados obtidos; (v) elaboração da demonstração do Valor Econômico Agregado em conjunto com as demonstrações financeiras da entidade no exemplo desenvolvido; (vi) aplicação prática dos ajustes propostos partindo de demonstrações financeiras publicadas e análise dos resultados obtidos.

De acordo com Stewart (1990) há evidências sugestivas de que o $E V A^{\circledR}$ é a chave para o sucesso das empresas, onde o valor de mercado excede os recursos próprios comprometidos à empresa. Tanto a teoria quanto as pesquisas apontam para a mesma conclusão: o EVA deveria ser adotado como o objetivo predominante de qualquer companhia que tenha como objetivo a maximização da riqueza do shareholders. 
Diante de tais considerações, o estudo atingiu seus objetivos de enaltecer a teoria e a utilização da contabilidade na moderna visão de criação de valor, tornando-se indispensável e útil para os executivos e investidores. Além de ter mantido uma forte interdisciplinaridade no estudo da contabilidade e finanças. A premissa fundamental do trabalho científico, além da consistência teórica, é justificar aplicabilidade prática. Neste estudo, ob- serva-se o atendimento às duas questões anteriormente ressaltadas.

Não obstante, apesar das limitações já abordadas nos tópicos anteriores, presume-se que o estudo tenha dado uma contribuição efetiva para a contabilidade, sendo direcionador de futuros estudos e trabalhos aprofundados na área, enaltecendo, assim, a atividade contábil e contribuindo para uma melhor gestão empresarial.

\section{REFERÊNCIAS BIBLIOGRÁFICAS}

ALMEIDA, Lauro Brito, PARISI, Cláudio e PEREIRA, Carlos Alberto. CATELLI, Armando (coord.). Controladoria - Uma Abordagem da Gestão Econômica. FIPECAFI. São Paulo: Atlas, 1999, pág.369-381.

ARAUJO, Adriana Maria Procópio de. Ajustes da Contabilidade Tradicional para uma Contabilidade Baseada em Valor. 2002. Tese (Doutorado em Controladoria e Contabilidade) - Faculdade de Economia, Administração e Contabilidade da Universidade de São Paulo, São Paulo.

AMERICAN Institute of Certified Public Accountants. Basic concepts and accounting principles underlying statements of business enterprises. APB Statement n 4, AICPA, 1970.

ASSAF NETO, Alexandre. Estrutura e Análise de Balanços. 5. ed., São Paulo: Atlas, 2000.

CATELLI, Armando (coord.). Controladoria - Uma Abordagem da Gestão Econômica. FIPECAF. São Paulo: Atlas, I, 1999.

COPELAND, Tom, KOLLER, Tim e MURRIN, Jack. Avaliação de Empresas - Valuation. Tradução: Maria Cláudia S.R. Ratto. McKKinsey \& Company, Inc., São Paulo: Makron Books, 2000.

DAMODARAN, Aswath. Avaliação de Investimentos - Ferramentas e Técnicas para a determinação do valor de qualquer ativo. Tradução: Carlos Henrique Trieschmann e Ronaldo de Almeida Rego. Rio de Janeiro: Qualitymark, 1997.

EHRBAR, Al. EVA: valor econômico agregado: a verdadeira chave para a criação de riqueza. Rio Janeiro: Qualitymark, 1999.

FISHER, Irving. A Teoria do Juro. São Paulo: Nova Cultural, 1988.

GITMAN, Lawrence J. Princípios de Administração Financeira. 7. ed., São Paulo: Harbra, 1997.

GRANT, James L. Foundations of Economic Value Added. New Hope, Pennsylvania: By Frank J. Fabozzi Associates, 1997.

GUERREIRO, Reinaldo; CATELLI, Armando (coord.). Controladoria - Uma Abordagem da Gestão Econômica. FIPECAFI. São Paulo: Atlas, 1999, p. 81-102.
HENDRIKSEN, Eldon. Accounting Theory. 4. ed., Illinois: Irwin, 1982.

. \& VAN BREDA, Michael F. Teoria da Contabilidade. São Paulo: Atlas, 1999.

HICKS, Valor y capital. Fondo de Cultura Económica, México: Buenos Aires, 1954.

Value and Capital. Oxford: Clarendon Press, 1946.

HORNGREN, Charles T., FOSTER, George e DATAR, Srikant M. Contabilidade de Custos. 9a ed., Rio Janeiro: LTC, 2000.

IUDíCIBUS, Sérgio de. Teoria da Contabilidade. 3. ed., São Paulo: Atlas, 1993.

LOPO, Antônio; BRITO, Lauro; SILVA, Paulo Roberto; MARTINS, Eliseu (Org.). Avaliação de Empresas: Da Mensuração Contábil à Econômica. FIPECAFI. São Paulo: Atlas, 2001, p.186-262.

MARTINS, Eliseu. Contribuição à Avaliação do Ativo Intangível. 1972. Tese (Doutorado em Contabilidade) - Faculdade de Economia, Administração e Contabilidade da Universidade de São Paulo, São Paulo.

\& ASSAF NETO, Alexandre. Administração Financeira - As finanças das empresas sob condições inflacionárias. São Paulo: Atlas, 1991.

(coord.). Avaliação de Empresas: da Mensuração Contábil à Econômica. SP: FIPECAFI, Atlas, 2001.

Extinção da correção monetária - Os juros sobre o capital próprio (TJLP) e os dividendos ( $1^{\mathrm{a}}$ e $2^{\mathrm{a}}$ parte). SP: Informações Objetivas, Caderno Temática Contábil e Balanços, Bol. 43/96 e 44/96, p. 426-446.

PEREIRA, Carlos Alberto; OLIVEIRA, Antônio Benedito Silva; CATELLI, Armando (coord.). Controladoria - Uma Abordagem da Gestão Econômica. FIPECAFI, São Paulo: Atlas, 1999, p. 414-426.

PORTERFIELD, James T.S. Decisões de Investimento e Custo de Capital. São Paulo: Atlas, 1976. 
RAPPAPORT, Alfred. Creating Shareholder Value. 2. ed., New York: The Free Press, 1998.

Gerando Valor para o Acionista. Tradução: Alexandre L.G. Alcântara. São Paulo: Atlas, 2001.

SOLOMON, Ezra. Teoria da Administração Financeira. 3. ed., São Paulo: Zahar, 1977.

Statement of Financial Accountig Standards. FASB- Financial Accounting Standards Board n.107. Disclosure about Fair Value of Financial Instruments. Stamford: Conn, 1991.

Statements on SMA/Institute of Management Accountants of Canada. Measuring and Managing Shareholder Value Creation. Statement 4AA, march 31, 1.997.

STERN \& STEWART \& Co./AL EHRBAR. EVA - The Real Key to Creating Wealth. New York: John Wiley \& Sons, 1.998.

STEWART, G. Bennett III. The Quest for Value. Harper Business, 1990.

\section{BIBLIOGRAFIA COMPLEMENTAR}

ASSAF NETO, Alexandre. Contabilidade Baseada em Valor. São Paulo: Anais do VI Congresso Brasileiro de Custos, FEA-USP, julho/1999.

Mercado Financeiro. 4. ed., São Paulo: Atlas, 2001.

BEUREN, Ilse Maria. Conceituação e Contabilização do Custo de Oportunidade. São Paulo: Caderno de Estudos FIPECAFI, $\mathrm{n}^{\circ}$ 08, abril/1993.

BREALEY, Richard A. \& MYERS, Stewart C. Princípios de Finanças Empresariais. 3. ed., Portugal: McGraw-Hill, 1992.

DONOVAN, John; TULLY, Richard; WORTMAN, Brent. The Value Enterprise. New York: McGraw-Hill Ryerson, 1998.

FREZATTI, Fábio. Valor da Empresa: Avaliação de Ativos pela Abordagem do Resultado Econômico Residual. São Paulo: Caderno de Estudos da FIPECAFI, no.19, set/dez-1998, v.10.

GUERREIRO, Reinaldo. Mensuração do resultado econômico. Caderno de Estudos FIPECAFI, São Paulo: FEA/USP, set.1991.

HIGUCHI, Hiromi \& HIGUCHI, Fábio Hiroshi. Imposto de Renda das Empresas - Interpretação e Prática. 22a ed., São Paulo: Atlas, 1997.

IUDíCIBUS, Sérgio de. Conceito Econômico e Contábil de Lucro: Simetrias e Arritmias. RBC - n.96, nov/dez. 1995, p.12 a 15, v.24.

MARTINS, Eliseu \& GELBCKE, Ernesto Rubens. Manual de Contabilidade das Sociedades por Ações: Aplicável às demais Sociedades. FIPECAFI. 5. ed., São Paulo: Atlas, 2000.
LEI das S/A. Manuais de Legislação, volume 28. $6^{\text {a }}$ ed., São Paulo: Atlas, 1999.

MARTINS, Eliseu. "EBITDA": o que é isso? São Paulo: Informações Objetivas, Caderno Temática Contábil e Balanços, Bol. 06/98, p. 01-07.

Por que o Balanço não Fornece o "Valor da Empresa"? São Paulo: Informações Objetivas, Caderno Temática Contábil e Balanços, Bol.18/92, p. 143-146.

ROSS, Stephen A., WESTERFIELD, Randolph W., JAFFE, Jeffrey F. - Administração financeira - Corporate Finance. São Paulo: Atlas, 1995.

SANVICENTE, A. Z.; MINARDI, A. M. A. F. Problemas de Estimação do Custo de Capital no Brasil. São Paulo: Instituto Brasileiro de Mercado de Capitais (IBEMEC), 1999.

SAUNDERS, Anthony. Administração de Instituições Financeiras. $2^{a}$ ed. Americana, Trad: Antonio Zoratto Sanvicente. São Paulo: Atlas, 2000.

SCHOEPS, Wolfgang. Quanto vale uma empresa? Rio de Janeiro: Revista de Administração de Empresas, FGV, ํo.04, 1972, v.12.

SECURATO, José R. Decisões Financeiras em Condições de Risco. São Paulo: Atlas, 1996.

<http:// www.cvm.gov.br/ acesso em 10 de agosto de 2001>.

$<$ http:// www.cfc.org.br/ acesso em 18 de agosto de 2001>. <http:// www.ibracon.org.br/ acesso em 03 de agosto de 2001>.

NOTA:

Endereço dos autores:

ADRIANA MARIA PROCÓPIO DE ARAÚJO

ALEXANDRE ASSAF NETO

Universidade de São Paulo - Campus Ribeirão Preto

Avenida dos Bandeirantes $n^{\circ} 3900$

Monte Alegre - Ribeirão Preto

14040900 - SP 